\title{
MATERIALIDADE, INTENÇÃO E CURA: O USO DE MEDICAMENTOS NO ESPIRITISMO BRASILEIRO
}

Waleska de Araújo Aureliano ${ }^{1}$

(UFSC)

Resumo: Neste artigo analiso o lugar dos medicamentos nas práticas terapêuticas do espiritismo brasileiro. Parto de uma revisão histórica da formação da doutrina no país e em pesquisa etnográfica realizada em um hospital espírita voltado para o atendimento de pessoas com câncer, localizado em Florianópolis (SC). Neste hospital, trabalham pessoas leigas, terapeutas diversos e profissionais de saúde oferecendo como tratamento cirurgias espirituais e terapias complementares, entre elas o uso de alguns medicamentos homeopáticos, fitoterápicos e florais. Ao considerar os processos sociais e simbólicos engendrados pelo uso de medicamentos na nossa sociedade e a histórica relação entre espiritismo e biomedicina no Brasil, minha intenção é analisar como se dão a produção, utilização e significação de substâncias medicamentosas em diferentes níveis (médico, religioso, político) nas práticas de cura espíritas desse hospital e o que essa dinâmica nos diz sobre as complexas relações entre os campos da religião e da saúde no país.

Palavras-chaves: Espiritismo, Medicamentos, Terapias Complementares, Câncer.

Abstract: In this article, I analyze the place of medicines in therapeutic practices of Brazilian Spiritism. I started from a historical review of the formation of doctrine in the country. Furthermore, I am based on ethnographic research conducted in a spiritist hospital for cancer patients, located in Florianópolis (Santa Catarina State). At this hospital, doctors, nurses, laymen, spiritualists and therapists work together and they conduct spiritual surgeries and various forms of complementary therapies as treatments, such as homeopathy, phytotherapy, and Bach flower remedies. In relation to the social and symbolic processes engendered by the use of medicines

\footnotetext{
${ }^{1}$ Doutora em Antropologia Social (PPGAS/UFSC), pesquisadora associada do Instituto Brasil Plural e TRANSES - Núcleo de Antropologia do Contemporâneo (UFSC). E-mail: waureliano26@yahoo.com.br.
} 
in Brazilian society, besides the historical relationship between Spiritualism and Biomedicine, my intention is to analyze how the production, the use and the meanings of medicinal substances operate at different levels (medical, religious, political) in regard to healing spiritist practices. I also intend to discuss how these practices reveal of the complex relationships between religion and health as social fields in Brazil.

Keywords: Spiritism, Medicines, Complementary Therapies, Cancer.

\section{INTRODUÇÃO}

O uso de medicamentos homeopáticos fez parte da formação do espiritismo brasileiro, tendo se constituído em uma prática largamente utilizada nos primeiros anos de difusão da doutrina no país e alvo de muitas disputas no campo da saúde entre médicos e terapeutas espíritas (Giumbelli, 1997; Warren, 1984; 1986). A mediunidade receitista, através da qual um médium, orientado por espíritos de médicos, receitava medicamentos, está presente na codificação da doutrina espírita escrita por Allan Kardec (1994) e no Brasil se fez bastante presente em muitos centros espíritas até meados do século XX.

No entanto, como forma de contornar os constantes embates com os representantes da medicina, na segunda metade do século XX, ocorreu a redução gradual dessa prática no espiritismo, o que não significou sua total supressão do seio do movimento espírita brasileiro. Muitos centros continuam a trabalhar com o uso de medicamentos homeopáticos associando-os a suas práticas tradicionais, como os passes e as cirurgias espirituais. Recentemente, medicamentos considerados complementares/alternativos, como os florais, passaram a fazer parte do rol de substâncias utilizadas nas práticas terapêuticas de alguns centros espíritas, colocando em contato formas tradicionais de cura espírita e práticas do universo da medicina alternativa complementar (MAC) que passaram a ser reconhecidas por organismos oficiais de saúde, a exemplo da Organização Mundial de Saúde (Who, 2002).

Como "coisas", os medicamentos facilitam processos simbólicos e sociais importantes na experiência daqueles que estão passando por estados 
de aflição e sofrimento (Van der Geest; White, 2011). No entanto, em contextos de cura espiritual a "materialidade" dos medicamentos pode ser afetada pelas associações que são feitas entre a eficácia considerada intrínseca a essas substâncias e a agência de outros seres como "espíritos", "energias" ou "o poder da mente". Como símbolos da moderna tecnologia biomédica, os medicamentos também dizem algo sobre a constante produção de semelhança e diferença em relação ao sistema médico oficial presente no espiritismo brasileiro, colocando em destaque as tensões políticas e os conflitos produzidos pelas intersecçóes que a doutrina espírita realizou aqui entre os campos da saúde e da religião.

Neste artigo, analiso o lugar dos medicamentos nas práticas terapêuticas do espiritismo brasileiro a partir de uma revisão histórica e da etnografia realizada em um hospital espírita voltado para o atendimento de pessoas com câncer, localizado em Florianópolis (SC). A intenção é analisar como se dá a produção, utilização e significação de substâncias medicamentosas em diferentes níveis (médico, religioso, político) e os modos como os sujeitos, produtores/prescritores e usuários, significam e se apropriam dos medicamentos que compõem a cena terapêutica desse hospital espírita.

O artigo está dividido em quatro partes. Remetendo a análises já realizadas por outros autores, na primeira parte, faço uma breve revisão histórica sobre a formação do espiritismo no Brasil, destacando como os medicamentos estiveram presentes nesse processo e que atualizações têm sido feitas contemporaneamente nas práticas de cura do espiritismo envolvendo o uso de substâncias medicamentosas. Em seguida, apresento o Centro de Apoio ao Paciente com Câncer (CAPC), hospital espírita que, dentre várias terapias complementares, oferece algumas medicaçóes como parte do seu tratamento espiritual. Na terceira parte, analiso o uso dessas medicações considerando o contexto maior do tratamento oferecido no CAPC e os agenciamentos realizados pelos atores em torno dessas substâncias. Por fim, nas consideraçôes finais, parto de uma imagem e do conceito de mimese em Taussig (1993) para pensar a constante produção de diferença e semelhança presente no espiritismo brasileiro em relação à biomedicina e seus símbolos. 


\section{MEDICAMENTOS, ESPÍRITOS E MÉDICOS: TRAJETÓRIAS DA TERAPÊUTICA ESPÍRITA NO BRASIL}

Segundo Aubrée e Laplantine (2009) seria apenas no Brasil que uma feição terapêutica do espiritismo se desenvolveu, já que a codificação de Allan $\operatorname{Kardec}^{2}$ apresentava uma explicação muito global e resumida da doença assim como oferecia poucos recursos aos médiuns para desenvolver atividades realmente terapêuticas. As doenças, especialmente as crônicas e degenerativas, poderiam ser vistas também como parte do carma individual não sendo, portanto, passíveis de serem curadas. Segundo os autores, essa concepção da doença poderia ser um dos motivos pelos quais a terapia espírita pouco se desenvolveu na França, por exemplo. No Brasil, ao contrário, a vertente terapêutica da religião aparece já nas primeiras fases de seu desenvolvimento no país e em parte está relacionada ao pressuposto da misericórdia e do perdão divinos herdados do catolicismo.

No entanto, devemos reconhecer que essa feição terapêutica não é exclusiva do espiritismo brasileiro. Em Porto Rico, esse mesmo caráter terapêutico do espiritismo apresenta-se de forma contundente, como atestam as pesquisas de Koss-Chinoino (2005), Rivera (2005) e Schmidt (2009). Também em Buenos Aires, Algranti (2007) apontou para as teorias etiológicas e as práticas terapêuticas desenvolvidas na Escuela Científico Basílio, instituição espírita fundada por um casal de franceses que migraram para Buenos Aires em finais do século XIX. Assim, talvez o que diferencie a terapêutica espírita no Brasil seja o seu considerável reconhecimento público, social e político como discutido por autores como Giumbelli (1997) e Aubrée e Laplantine (2009). Esse reconhecimento, no entanto, foi marcado por um longo processo de condenação e legitimação das práticas terapêuticas espíritas entre as quais se encontrava o uso de medicamentos.

O espiritismo considera que o ser humano é formado por uma tríplice dimensão que envolve o corpo físico (material e transitório), o espírito (fluí-

\footnotetext{
${ }^{2}$ Allan Kardec é o pseudônimo do pedagogo Hippolyte Léon Denizard Rivail, considerado o codificador das mensagens e orientações dos espíritos que deram origem ao espiritismo na França em meados do século XIX.
} 
dico e imortal) e o perispírito, corpo energético situado a meio caminho entre o corpo material e o espiritual e responsável pela união e pelo equilíbrio de ambos. O perispírito seria o intermediário através do qual o “[...] espírito transmite sua vontade ao exterior e age sobre os órgãos" (Kardec, 1994, p. 63). Quando não há um equilíbrio perfeito entre essas três dimensões do ser, abre-se espaço para as doenças, que podem ser: a) fruto de ações do sujeito praticadas na vida atual que comprometeram o equilíbrio entre corpo, mente e espírito; b) perturbações provocadas por espíritos desencarnados que, motivados por dívidas cármicas, agem sobre os encarnados provocando desequilíbrios de ordem espiritual e mental que podem levar às doenças físicas; e c) as doenças cármicas provenientes da escolha do próprio espírito quando de sua reencarnação que teriam por propósito redimir faltas graves cometidas em uma encarnação anterior.

Quanto às formas de tratamento capazes de proporcionar curas, a obra kardequiana menciona o passe e a prece. No Brasil, os espíritas encarregaramse de ampliar o escopo terapêutico da doutrina desenvolvendo práticas para tratar as mais diversas enfermidades. A principal delas seria a desobsessão, técnica na qual um médium incorpora o espírito obsessor e outro faz a doutrinação desse espírito através de uma conversa na qual os valores cristãos do perdão e do amor ao próximo, por exemplo, vão ser utilizados como argumentos para persuadir o obsessor a desistir da sua vingança.

No entanto, além dessas práticas, os primeiros espíritas brasileiros também aplicavam o receituário mediúnico através do qual um médium incorporado ou intuído pelo espírito de um médico receitava medicamentos, na maioria das vezes homeopáticos e, eventualmente, também alopáticos. Esses médiuns são conhecidos como médiuns receitistas, sendo "[...] sua especialidade servir mais facilmente de intérprete dos Espíritos para as prescrições médicas" (Kardec, 1994, p. 215). Deste modo, ao lado da desobsessão e dos passes, a prática da homeopatia foi um dos carros-chefes da terapêutica espírita no início de sua expansão pelo Brasil.

A homeopatia está baseada no conceito de vitalismo, muito difundido em finais do século XVIII e início do XIX, que postulava a existência de uma força ou impulso vital sem a qual a vida não poderia ser explicada. Luz 
(1988; 1996), no entanto, fala em vitalismo homeopático para distingui-lo das diversas correntes vitalistas contemporâneas de Samuel Hahnemann (mesmerismo, magnetismo, geração espontânea), o médico criador da homeopatia. O vitalismo homeopático trataria do equilíbrio da "força vital" do indivíduo, força de natureza imaterial que quando em desarmonia leva aos estados patológicos. Neste caso, a doença deixa de ser o foco de especulação e a atenção volta-se para o sujeito que deve ter sua força vital reestabelecida para que se processe a autocura e o adoecer é visto como um processo vital do indivíduo no sentido de se equilibrar como totalidade biopsíquica (Luz, 1988) .

Essas características da homeopatia baseadas em princípios não materiais, mas sim energéticos e imateriais, teria proporcionado uma boa aceitação da medicina homeopática pelos espíritas brasileiros que passaram a considerá-la como a única forma de medicina espiritualista. Pesquisadores como Luz (1988; 1996) e Warren (1984; 1986), no entanto, abordam essa relação entre espiritismo e homeopatia no Brasil realizando um esforço em separar uma coisa da outra.

Warren afirma que o aspecto científico da homeopatia foi obscurecido no Brasil graças aos primeiros homeopatas europeus que aqui se instalaram a partir de meados do século XIX e conferiram "tal mística aos remédios homeopáticos" que até 1970 o que prevaleceu no país foi "[...] uma forma espiritualizada de homeopatia" (Warren, 1986, p. 88). O autor atribui essa mistificação ao que denomina de espiritualismo reflexivo dos brasileiros, ou seja, uma disposição inata para explicar e interpretar sua sorte a partir de um universo no qual a relação com espíritos, fantasmas e almas penadas seria uma constante para os contemporâneos dos primeiros divulgadores da homeopatia que souberam aproveitar esse "traço" da nossa "cultura". Essa "mística" teria sido reforçada pela absorção irrestrita da homeopatia pelo

\footnotetext{
${ }^{3}$ Esta é uma explicação bastante resumida e parcial de apenas um dos princípios da homeopatia. Para uma análise social da homeopatia enquanto sistema médico e sua expansão no Brasil, ver Luz (1996). Para uma análise da relação entre homeopatia e espiritismo ver Aubrée e Laplantine (2009).
} 
movimento espírita que a introduziu como forma de tratamento em seus centros através do receituário mediúnico.

Já Luz, coloca ênfase no fato de que a homeopatia se desenvolve e chega ao Brasil bem antes do lançamento e da divulgação da obra de Allan Kardec na França, não sendo, portanto, um sistema médico derivado do espiritismo, o qual ela denomina em determinado momento de "seita" (Luz, 1996, p. 95). No entanto, os dois autores reconhecem que no desenvolvimento da homeopatia no Brasil surgiram diversas correntes de praticantes, umas reivindicando o caráter científico da medicina homeopática e buscando afastá-la de qualquer "misticismo espírita" e outras de cunho abertamente espiritualista, de modo que não haveria um consenso teórico ou uma unidade entre seus praticantes.

Até 1942 o código penal brasileiro associava a prática do espiritismo ao exercício ilegal da medicina quando esta se prestava a "[...] inculcar a cura de moléstias curáveis ou incuráveis [...]” e “[...] aplicar ou prescrever substâncias com fins terapêuticos". Como demonstrou Giumbelli (1997), o receituário mediúnico, largamente pautado na prescrição de remédios homeopáticos, perde gradualmente espaço dentro da Federação Espírita Brasileira (FEB) e dos centros a ela filiados nos anos 1940, em parte, em função das necessárias adequações que o espiritismo se viu obrigado a operar na sua relação com o Estado a fim de não sofrer sanções e acusações de prática ilegal da medicina. Por outro lado, Giumbelli também aponta para as determinaçōes internas aos grupos espíritas que levaram a uma atenuação gradual do uso do receituário mediúnico. Com o desenvolvimento mais ordenado de atividades de cunho moral-espiritual e doutrinário como os conselhos pessoais, as visitas domiciliares e a desobsessão, o fortalecimento das atividades assistenciais com a criação de escolas, asilos e orfanatos, além das formas mais institucionalizadas de prestação de serviços por profissionais da área de saúde, a mediunidade receitista perde gradualmente terreno dentro da Federação e dos centros a ela afiliados em meados do século XX:

Colocadas frente a frente, essas modalidades produziam uma delimitação mais rigorosa entre as dimensões "espirituais" e "materiais" que não era 
absolutamente respeitada por algo como a "mediunidade receitista" exemplo paradigmático de prática informada por uma concepção "espiritualizada da matéria" (o "conselho mediúnico" para a doença do corpo) e a "materialização do espírito" (a ação de um medicamento sobre "fluidos" humanos). Deteriorada em suas franjas por um processo complexo e longo, a "mediunidade receitista" finalmente sucumbiu quando atingida em seu centro pelas proibições penais e as exigências policiais (Giumbelli, 1997, p. 266).

No entanto, é preciso notar que a diminuição gradativa do uso do receituário mediúnico nos anos 1940 não significou a extinção dessa prática terapêutica dentro do espiritismo brasileiro. Giumbelli (1997) traz dados de uma pesquisa realizada pelo ISER entre 1994 e 1995 com cem centros espíritas no estado do Rio de Janeiro na qual 10\% dos grupos investigados declararam oferecer o receituário mediúnico. $\mathrm{Na}$ internet, uma busca rápida pelo Google aponta para centenas de referências ao uso da mediunidade receitista e do receituário mediúnico ainda presente em muitos centros espíritas.

A sede histórica da FEB no Rio de Janeiro ainda oferece o receituário mediúnico prescrevendo medicações homeopáticas. Para solicitar uma receita, a pessoa precisa preencher uma folha que é entregue na secretaria da instituição com seus dados (nome, idade, endereço). Não é necessário mencionar uma doença. Depois de uma semana, a receita pode ser retirada na própria secretaria e o medicamento homeopático comprado em qualquer farmácia especializada.

Em visita à instituição, disse à secretária que me atendeu que eu acreditava que o receituário mediúnico estava suspenso, pois não havia encontrado no site da FEB qualquer menção a esta prática ${ }^{4}$. Segundo ela, a atividade jamais havia sido suspensa, o que teria acabado "[...] há uns 50 anos [...]" foi a produção e distribuição dos remédios homeopáticos na FEB. No entanto, não deixa de ser emblemático que a prática não seja divulgada oficialmente. É possível encontrar indicaçōes sobre o receituário mediúnico na FEB em listas de discussões espíritas espalhadas pelas redes

\footnotetext{
${ }^{4}$ Disponível em: http://www.febnet.org.br/site/. Acesso em 03 maio 2012.
} 
sociais nas quais os adeptos informam como as pessoas podem obter a receita homeopática na sede carioca. Porém, não há qualquer registro no site oficial da Federação sobre o receituário mediúnico, nem mesmo no dicionário de verbetes Espiritismo de $A$ a $Z$. Esse fato aponta para a discrição que passou a envolver o uso do receituário mediúnico no espiritismo e que merece ser analisada, levando-se em conta que a homeopatia é hoje em dia reconhecida como uma especialidade médica, ao contrário do que ocorria nos anos 1940, o que possivelmente também afeta o modo como o receituário é praticado atualmente na FEB. $\mathrm{O}$ fato deles não mais entregarem a medicação, mas apenas a receita, também diz algo sobre a evitação de possíveis conflitos com os produtores e distribuidores dessas medicações.

Neste sentido, é preciso ter em mente que o uso de medicamentos nas práticas terapêuticas do espiritismo caminha lado a lado com a presença dos médicos, encarnados e desencarnados, que também povoam as práticas da doutrina. A relação entre médicos e espíritas deve ser pensada dentro de um contexto histórico de demarcação e fortalecimento do próprio campo acadêmico da medicina no país durante o século XIX e início do século XX. A formação de médicos no Brasil se dá a partir de 1808, quando a família real portuguesa transfere-se para a colônia, fugindo das guerras napoleônicas. Antes disso, os poucos médicos que existiam no Brasil eram formados nas universidades da Europa e concorriam de perto com uma vasta gama de curadores populares, tais como as benzedeiras, os erveiros e os cirurgiōesbarbeiros (Montero, 1985). A partir do século XX, o espiritismo passa a fazer parte da lista das formas terapêuticas combatidas pelos médicos brasileiros, na tentativa de estabelecer o controle do campo da saúde no Brasil.

No entanto, as ligações entre médicos e espíritas não foram feitas apenas de conflitos. As primeiras traduções da obra de Kardec no Brasil foram realizadas pelo médico Joaquim Carlos Travassos e um dos grandes divulgadores do espiritismo em solo brasileiro foi o médico Adolfo Bezerra de Menezes, considerado o Kardec brasileiro. Os médicos espíritas brasileiros estão organizados hoje me dia em torno da Associação Médico-Espírita do Brasil (AME-Brasil), cuja missão seria 
[...] promover o estudo da Doutrina Espírita e de sua fenomenologia, tendo em vista suas relaçõos, integração e aplicação nos campos da filosofia, da religião e da Ciência, em particular da Medicina, procurando fundamentá-la através da criação e realização de estudos e experiências orientadas nessa direção".

Atualmente, existem 48 seccionais da AME espalhadas por todos os estados brasileiros.

A relação entre medicina e espiritismo no Brasil não envolve apenas os médicos encarnados. Como escrito anteriormente, na prática receitista, por exemplo, os medicamentos são geralmente prescritos por espíritos de médicos, através da incorporação em um médium. Os médicos desencarnados também estão presentes na prática da cirurgia espiritual, que no Brasil alcançou grande visibilidade na mídia a partir da figura do Dr. Fritz, o espírito de um médico alemão que teria morrido durante a I Guerra Mundial e que, através da incorporação em vários médiuns ao longo dos últimos 60 anos já realizou milhares de cirurgias utilizando-se de facas de cozinha e até serra elétrica, sem a utilização de anestesia ou qualquer técnica de assepsia ${ }^{6}$.

De modo geral, as cirurgias espirituais, assim como as demais terapias oferecidas pelos centros espíritas, não são cobradas. A caridade seria o elemento que rege tais práticas e a cobrança caracterizaria definitivamente a prática mediúnica da cirurgia espiritual como exercício ilegal da medicina, por isso os médiuns não costumam cobrar. No entanto, doações espontâneas dos doentes são bem-vindas e algumas cirurgias são acompanhadas de recomendações para uso de medicamentos "naturais", geralmente chás, fitoterápicos ou homeopáticos que são vendidos pelos próprios médiunscirurgiōes. Aqui ressurge o uso do medicamento na terapia espiritual e sua relação com os médicos, encarnados ou desencarnados.

\footnotetext{
${ }^{5}$ Disponível em: site www.amebrasil.org.br. Acesso em: 20 abr 2008. Para uma análise sobre os médicos espíritas e a Associação Médico-Espírita do Brasil, ver Soares (2009).

${ }^{6}$ Há outros tipos de cirurgias espirituais ocorrendo no Brasil nas quais não são realizados cortes ou perfurações, como nas cirurgias fluídicas ou astrais que seriam realizadas diretamente pelos espíritos sem interferência dos médiuns.
} 
É o que acontece no centro do médium João Teixeira de Faria, conhecido internacionalmente por João de Deus, localizado em Abadiânia (GO), onde os pacientes são geralmente orientados a comprar cinco frascos de cápsulas de passiflora (maracujá) como complemento à cirurgia espiritual. Cada frasco custa em média $\mathrm{R} \$ 10,00$, mas só pagariam aqueles que têm condiçôes financeiras para tal (Moreira-Almeida et al., 2000). As cápsulas de passiflora também são levadas para outros países por estrangeiros que frequentam o centro de João de Deus em busca de tratamento para eles mesmos ou para familiares e amigos que não podem vir ao Brasil. Neste caso, as pessoas enviam suas fotografias para serem mostradas ao médium e "[...] todos que mandam fotos recebem uma receita de remédios [...]", gerando "um trânsito de fotos em um sentido e de remédios no outro" (Rocha, 2009, p. 584).

O uso de medicamentos também faz parte dos atendimentos prestados pelo médium Chico Monteiro, em Rio Novo (MG). Esse médium também realiza cirurgias incorporando o espírito do Dr. Fritz, mas sem realizar cortes e perfuraçôes. Como João de Deus, Chico Monteiro prescreve medicamentos em seu centro que levam a chancela da Farmácia Homeopática. No entanto, os pacientes não são obrigados a adquirir os medicamentos na farmácia do médium e, segundo Cruz (2007), muitos pacientes não levam em conta o tratamento medicamentoso de Chico Monteiro estando mais preocupados em serem submetidos à cirurgia espiritual.

Greenfield (1999), analisando vários médiuns-cirurgiōes no Brasil, mostra que a prática de receitar medicamentos alopáticos era comum entre alguns deles e que alguns desses medicamentos eram "[...] tão novos que só poderiam ser encontrados, se o fossem, em centros metropolitanos do sul [do Brasil] onde as grandes companhias multinacionais têm seus laboratórios" (idem, p. 25). O médium e também médico Edson de Queiroz, por exemplo, receitava grandes quantidades de medicamentos aos pacientes operados por ele com auxílio do Dr. Fritz. Segundo Greenfield (idem, p. 42), a instituição espírita na qual o médium atendia fornecia a medicação para os pacientes mais pobres graças a doações que recebia de laboratórios 
farmacêuticos. Apesar de Edson ser médico, quem assinava as receitas era um patologista que acompanhava suas cirurgias.

A partir dessas relações de conflito e aliança entre espíritas e médicos, e considerando o lugar central que a biomedicina e seus símbolos ocupam na formulação do espiritismo no Brasil, passo agora a analisar o lugar dos medicamentos em um centro de tratamento espírita voltado para pacientes com câncer localizado no sul do país.

\section{SAÚDE E ESPIRITUALIDADE: O CENTRO DE APOIO AO PACIENTE COM CÂNCER (CAPC)}

O CAPC foi fundado em março de 1998, no bairro do Ribeirão da Ilha, na parte insular de Florianópolis e está vinculado ao Núcleo Espírita Nosso Lar (NENL) localizado na cidade de São José, distante apenas nove quilômetros de Florianópolis. $\mathrm{Na}$ época desta pesquisa, o CAPC atendia em média 100 pacientes por semana, oriundos não apenas de Florianópolis, mas de outras cidades catarinenses, dos estados vizinhos e, eventualmente, de outros países.

Para iniciar seu tratamento no CAPC, o paciente com câncer deve passar por um atendimento prévio no NENL, onde seus exames clínicos são analisados. O CAPC não realiza atendimento sem a apresentação desses exames que vão nortear as aplicações terapêuticas, as cirurgias espirituais e comprovar que a pessoa está sendo acompanhada por médicos. O tratamento inicia-se às terças-feiras e termina aos sábados. Durante a semana, os pacientes ficam internados no regime hospital-dia: recebem as terapias ao longo do dia e retornam para casa no início da noite. O CAPC oferece cerca de 20 terapias complementares, algumas bastante conhecidas, como os florais de Bach, a cromoterapia e o reiki, além das terapias espíritas tradicionais como os passes e a água fluidificada. Apenas nas sextas-feiras os pacientes pernoitam no CAPC para serem submetidos à cirurgia espiritual que é realizada sem cortes ou qualquer procedimento invasivo.

No CAPC trabalham vários profissionais de saúde, terapeutas diversos e pessoas leigas que são treinadas para a aplicação das terapias. Os profissionais 
da limpeza, da cozinha e a equipe de enfermagem são remunerados, todos os demais trabalhadores são voluntários, inclusive os médicos que atuam tanto dentro da sua profissão, realizando análise de exames e atendimento médico aos pacientes, quanto na aplicação das terapias complementares, sendo alguns deles os médiuns que realizam as cirurgias espirituais. Apesar de ser uma instituição ligada ao espiritismo, não há impedimento para que pessoas de outras religiōes trabalhem como voluntárias no CAPC que é apresentado como espaço terapêutico, e não de doutrinação espírita. Assim, há voluntários que se definem como católicos, umbandistas, budistas ou sem religião específica, denominando-se espiritualistas.

O CAPC assemelha-se a um hospital ou clínica. Uma forte conexão com símbolos biomédicos pode ser observada na organização do espaço físico (enfermaria com 57 leitos, salas de cirurgia, sala de espera e auditório), no modo de vestir dos voluntários (roupa branca, jaleco, máscaras e touca), na hierarquização das funçōes (médiuns operadores, médiuns doadores, instrumentadores cirúrgicos, auxiliares técnicos, leitor/a de prontuários) e na forma como as cirurgias espirituais são realizadas (em macas, com uso de iodo, gazes, bisturis de fio cego, curativos, emissão de atestados e orientaçôes pós-cirúrgicas). O Centro dispõe ainda de uma sala equipada com aparelhos específicos para atendimentos de urgência e de uma ambulância, elementos que reforçam sua identidade enquanto uma instituição terapêutica capaz de prestar atendimento a pessoas com doenças graves como o câncer.

Todo atendimento oferecido no CAPC é gratuito e a instituição é mantida através de doações, mensalidade de sócios efetivos, subvenções e trabalho voluntário. O Centro é reconhecido como instituição de utilidade pública por sua atuação terapêutica assistencial na cidade de Florianópolis, o que demonstra seu reconhecimento social e político.

Embora o ápice do tratamento oferecido no CAPC seja, sem dúvida, a cirurgia espiritual, há uma série de terapias que compõem esse tratamento e que são encaradas como uma preparação do corpo, da mente e do espírito para o recebimento da cirurgia espiritual ou como forma de auxiliar e potencializar seus efeitos. Entre essas terapias estão algumas que denominei de medicamentosas por envolverem a ingestão de substâncias que teriam 
propriedades curativas, indo da água fluidificada aos fitoterápicos e medicações desenvolvidas pelo próprio CAPC e que descrevo a seguir:

A água fluidificada - Na doutrina espírita, a água aparece como substância privilegiada para receber os "fluidos salutares" que podem ser transmitidos pelos espíritos e/ou pelos médiuns, e até mesmo por qualquer pessoa que esteja imbuída de bons pensamentos e intenção de cura em benefício do próximo ${ }^{7}$. No CAPC, os pacientes recebiam um frasco com água fluidificada já no primeiro dia de tratamento e deveriam, em casa, misturá-la a um litro de água mineral. Essa água deveria ser ingerida em pequenas doses, três vezes ao dia, durante 30 dias. Como um litro de água não é suficiente para todo esse tempo, antes da água acabar o paciente deveria se dirigir ao NENL, em São José, para pegar um novo frasco de água fluidificada, na farmácia do Núcleo e repetir o procedimento.

A água também estava presente em outra importante terapia do CAPC, a hidroterapia. No decorrer da semana, os pacientes tomavam a hidroterapia duas vezes ao dia. Além de receber os "fluidos curadores", através da imposição de mãos de um médium, a água utilizada nesta terapia era acrescida de gotas de outras águas extraídas de cristais, pedras preciosas, semipreciosas, água do degelo, água que ficou depositada no fundo do mar e depois foi trazida à superfície. Essas águas passaram por processos diferentes para "captar e dinamizar energias curadoras" presentes em minerais e em locais da natureza, como as montanhas e o mar. Segundo o dirigente geral do CAPC, a hidroterapia seria uma das principais terapias oferecidas na casa, pois ela prepararia o corpo do paciente para receber as demais terapias ao "abrir seus campos energéticos". A hidroterapia era feita de forma individualizada, não havia uma fórmula padrão, cada frasco era preparado a partir do prontuário do paciente e de acordo com seu "histórico clínico", que só

\footnotetext{
${ }^{7}$ É interessante notar que a água como fonte de cura não é algo presente apenas no espiritismo. Entre os católicos, a fonte do santuário de Lourdes, localizada na França, atrai milhares de fiéis e doentes do mundo inteiro em busca da sua água milagrosa. Em programas católicos e evangélicos de rádio e TV, os fiéis são orientados a colocar um copo com água próximo ao aparelho para que ela seja abençoada e possa ser utilizada com diversas finalidades, inclusive para o alívio de uma doença.
} 
poderia ser devidamente analisado por uma pessoa treinada para manipular e ministrar essa terapia.

Florais de $\mathrm{Bach}^{8}$ - Durante a semana de tratamento no CAPC, alguns pacientes eram convidados a participar de uma Roda de Florais. Essa roda era conduzida por duas terapeutas de florais e reunia em grupo cerca de 20 pacientes. Normalmente, as pessoas selecionadas para Roda de Florais eram aquelas que se mostravam muito emotivas no primeiro dia de internação, que choravam ou falavam abertamente que estavam desmotivadas ou desesperadas diante do diagnóstico do câncer e do seu tratamento como um todo. Na Roda, as pessoas eram instadas a se apresentar e falar sobre seus sentimentos, dizer que emoções estavam sentindo naquele momento e o que lhes afligia. Com base nessas informações, os florais eram preparados e distribuídos aos pacientes.

As terapeutas apresentavam os florais de Bach como remédios que ajudariam os pacientes a "romper bloqueios emocionais", "liberar emoções reprimidas", "trazer conforto emocional durante o tratamento", entre outras funções sempre relacionadas a aspectos emocionais. No entanto, as terapeutas enfatizavam que o "floral sozinho não faz nada", que a pessoa deveria estar atenta às suas emoçōes e disposta a mudar certas atitudes, certos pensamentos e comportamentos que talvez estivessem favorecendo seu adoecimento ou dificultando sua cura. Sem essas mudanças, o paciente poderia "tomar baldes de floral" e não iria adiantar nada.

Embora não fossem feitas menções específicas ao espiritismo ou qualquer religião, a Roda de Florais era bastante marcada por uma "conversa" de feições religiosas, com citaçóes a Jesus e na qual sentimentos como raiva, tristeza, mágoa, perdão e culpa podiam ser tratados tanto a partir da ótica

\footnotetext{
${ }^{8}$ Os florais são extratos de flores criados pelo médico inglês Edward Bach, nos anos 1930, e têm como propósito terapêutico agir sobre os estados emocionais dos pacientes. Para Bach, os problemas de saúde tinham sua origem na mente e nos sentimentos reprimidos que emergem gerando conflitos mentais e, posteriormente, doenças físicas. Os Florais de Bach chegaram ao Brasil no início da década de 1990 e atualmente existem diversos tipos de florais, além das essências criadas pelo Dr. Bach (Florais de Saint Germain, Florais da Deusa, Florais da Califórnia).
} 
da psicossomática quanto do cristianismo e de preceitos do espiritismo, como a reforma íntima, embora sem menção direta à doutrina espírita. O floral era apresentado como "uma ferramenta" de ajuda para o autoconhecimento, requisito necessário ao bom manejo dos estados emocionais e, consequentemente, da saúde física. A fé na cura também aparecia aqui enquanto elemento importante para potencializar não apenas o efeito dos florais, mas de qualquer medicação.

O floral também era utilizado em uma inalação que os pacientes faziam minutos antes da cirurgia espiritual. A essência utilizada nessa inalação era a Rock Rose que, na descrição dos florais de Bach, seria "o remédio da salvação" (Bach, 2006, p. 75).

Fitoterápicos, alopáticos e os "medicamentos da casa" - O NENL possui um laboratório no qual produz cerca de 150 fitoterápicos com base na utilização de 209 ervas. Anualmente 100 mil unidades desses medicamentos são distribuídos gratuitamente em forma de cápsulas, líquidos, pomadas e unguentos às centenas de pessoas que fazem tratamento na casa, incluindo os pacientes do CAPC. Neste laboratório, trabalhavam cerca de 50 voluntários sob a supervisão de três bioquímicos. Havia um controle estrito sobre a distribuição desses medicamentos, para que eles não fossem utilizados por pessoas que não estivessem em tratamento na casa. Até mesmo os voluntários precisavam recorrer a autorizaçóes específicas para solicitar esses medicamentos na farmácia do NENL, que geralmente eram prescritos por terapeutas que fizeram algum tipo de treinamento específico. Segundo o dirigente geral do NENL/CAPC, não haveria nesse processo interferência dos espíritos, os receitistas da casa não eram necessariamente médiuns e, segundo ele, alguns não seriam nem mesmo espíritas, mas sim pessoas "treinadas academicamente para prescrever fitoterápicos".

As duas terapias medicamentosas mais importantes oferecidas pelo CAPC eram o Ipê Roxo (IR) e o SYG. Esses dois medicamentos eram produzidos em laboratório próprio nas dependências do CAPC. O primeiro é um fitoterápico produzido a partir de uma tintura extraída do Ipê Roxo e utilizado apenas pelos pacientes com câncer. Os pacientes não levavam o IR para casa, como faziam com a água fluidificada ou os fitoterápicos, 
eles ingeriam a medicação durante o período de tratamento no CAPC. Essa restrição deu-se por conta da patente de uma substância presente na composição do IR que, segundo o dirigente do CAPC, foi cedida por um laboratório da Inglaterra que os ajudou na formulação do medicamento sob a condição de proteção da fórmula.

Por fim, o SYG seria, nas palavras da voluntária que produz, distribui e orienta sobre a utilização desse medicamento, "a menina dos olhos" do CAPC. É o único medicamento homeopático da casa e seria, segundo o dirigente do CAPC, "similar, mas completamente diferente" ao método Canova utilizado também para tratamento do câncer e doenças imunodepressoras, muito popular no Brasil, que age sobre o sistema imunológico, a fim de mobilizar as próprias defesas do organismo. Apenas alguns pacientes eram selecionados para tomar esse medicamento que consiste em cinco frascos com medicação líquida que deve ser ingerida em gotas, cada frasco em dias alternados e com número de gotas diferentes. O nome do remédio, SYG, é formado pelas iniciais dos três mentores espirituais do NENL/CAPC: Savas, Yura e Gabriel.

Nem o NENL nem o CAPC possuem licença oficial da vigilância sanitária para produzir e distribuir medicação homeopática ou fitoterápica, porém, em mais de 30 anos atuando na cidade de São José e há 13 anos em Florianópolis, eles só teriam enfrentado uma denúncia feita pelo proprietário de uma farmácia que se sentiu prejudicado pela distribuição gratuita de fitoterápicos no NENL. Segundo o dirigente geral, a situação foi resolvida a partir da redução da divulgação desses medicamentos entre os pacientes e da implantação de formas mais restritivas para sua distribuição.

A utilização de medicamentos alopáticos também estava presente no CAPC, pois muitos pacientes faziam uso de medicação controlada que era trazida para o Centro durante a semana de tratamento. A equipe de enfermagem buscava certificar-se de que o paciente não se esquecesse de fazer uso dessa medicação checando, em alguns casos, os horários de tomada do medicamento. Havia uma farmácia no CAPC, cujo acesso era restrito aos médicos e enfermeiras, com uma série de remédios alopáticos que eventualmente eram utilizados, especialmente analgésicos. Porém, a recomendação 
era para que os pacientes trouxessem sua própria medicação alopática indicada pelo médico que acompanhava seu tratamento. Até mesmo para os voluntários, o uso da medicação alopática era restrito e deveria passar pela avaliação do médico ou da médica de plantão. Quando solicitei certo dia um Dorflex (analgésico e relaxante muscular) para uma das enfermeiras, por estar com dor de cabeça, ela só me forneceu a medicação depois de consultar o médico de plantão, embora eu tenha lhe assegurado que fazia uso dessa medicação regularmente, por conta própria.

\section{MATERIALIDADE E INTENÇÃO: OS MEDICAMENTOS E O TRATAMENTO ESPIRITUAL}

Van der Geest e Whyte (2011) afirmam que a chave para o "encanto" dos medicamentos, especificamente em suas análises dos medicamentos alopáticos, está na sua concretude, no fato deles serem capazes de objetificar a cura e poderem ser utilizados por qualquer pessoa que esteja de sua posse, quebrando de certa forma a hegemonia dos profissionais de saúde. Como "coisas", os medicamentos passam de um contexto de significado a outro e podem ser utilizados e interpretados de diferentes maneiras sem, contudo, perderem sua característica principal: o valor curativo que lhes é atribuído.

Nesse sentido, sendo os medicamentos "símbolos de saúde" (Lefévre, 1983), o fato deles aparecem de maneira tão forte e ao mesmo tempo diversificada nas práticas de cura do CAPC pode ser interpretado como uma forma particular da constante produção de semelhança e diferença impetrada pela doutrina espírita no Brasil com relação à biomedicina que pode ser observada também em outras práticas espíritas como as cirurgias espirituais, por exemplo, em que a presença de espíritos de médicos é tão comum.

No entanto, é preciso ter em mente que, no contexto das práticas espíritas de cura, uma possível "medicamentalização" do tratamento espiritual ocorre numa via de mão dupla, o que sugere que há também uma "espiritualização" do medicamento que, seja de que ordem for, é capturado de maneira polissêmica e utilizado dentro de um contexto terapêutico na qual 
o remédio por si só não pode ser considerado como agente fundamental de cura, mas como elemento que agrega valor a um tratamento por ser capaz de materializar agentes curativos numa substância.

No CAPC, os medicamentos também cumpririam com essa função "materializadora" da cura, embora dificilmente aparecessem como solução isolada para uma doença. Especialmente para os pacientes que se encontravam fora de possibilidades terapêuticas dentro da biomedicina, utilizar os medicamentos do CAPC seria uma maneira de objetificar a continuidade de um tratamento e de formas intencionais e renovadas de agência contra a doença quando os médicos já disseram que não havia mais nada a ser feito. Para outros que eram adeptos de longa data das medicinas alternativas, as medicaçôes alopáticas seriam antes símbolos de doença e não de saúde, de modo que se utilizar dos remédios fitoterápicos, homeopáticos ou "espirituais" que compõem o tratamento do CAPC era encarado como uma forma "natural" e menos agressiva de cuidar da saúde, embora a instituição apregoasse constantemente entre seus pacientes que o tratamento ali oferecido era complementar e não alternativo à biomedicina.

Além disso, no CAPC, as medicações estavam inseridas em um tratamento mais amplo e não poderiam ser pensadas fora desse contexto maior que envolveria também o tratamento convencional contra o câncer. Muitas vezes o que se ressaltava era que com o tratamento espiritual o paciente se tornava mais calmo e confiante no processo de cura de modo que seu corpo respondia melhor e mais rápido às medicações utilizadas no tratamento alopático contra o câncer, especialmente a quimioterapia:

Se o paciente está nervoso, está revoltado, está ansioso, com medo e infeliz, seu corpo não responde aos medicamentos. $\mathrm{O}$ estresse é tamanho que a medicação é toda eliminada pelos suores, pela urina, o organismo não absorve, não processa corretamente aquelas substâncias químicas. (...) Já há várias pesquisas que comprovam que os pacientes que também fazem um tratamento complementar e espiritual reagem melhor ao tratamento médico tradicional, precisam de menos medicamentos, menos analgésicos e se curam mais rapidamente. (Dirigente geral em palestra para os pacientes). 
Dessa forma, o que se ressaltava era a importância do tratamento espiritual como um todo e não apenas suas fórmulas medicamentosas. Estrategicamente, essa postura tanto preserva o lugar da biomedicina e de suas práticas como aponta para as especificidades do tratamento espiritual, garantindo-lhe um espaço diferenciado no rol das terapêuticas possíveis, incapaz de ser ocupado por formas terapêuticas como a biomedicina. Nesse sentido, a introdução de outras substâncias medicamentosas como a água fluidificada e os florais, por exemplo, seriam formas de "medicar" áreas não alcançadas pelos medicamentos "tradicionais", como os "campos energéticos" ou as emoções, ou de potencializar os efeitos do tratamento alopático, como vimos anteriormente. Assim, se por um lado resguardava-se um lugar para a biomedicina e seus medicamentos, por outro a validade e necessidade do tratamento espiritual e seus remédios também era colocada em pauta, sendo estes muitas vezes caracterizados pelo poder de potencializar as formas medicamentosas alopáticas.

No entanto, a eficácia dos medicamentos utilizados no CAPC não partiria da mesma lógica que faz do remédio alopático uma substância de ação independente da vontade do sujeito. Os florais, por exemplo, eram apresentados aos pacientes como remédios que necessitariam da ação do sujeito para a real ativação dos seus efeitos. Desse modo, ao mesmo tempo em que se atribuía poder curativo a uma substância, ela também poderia ser apresentada quase como inócua ao ter sua atuação terapêutica atrelada a exigências que demandavam da pessoa doente um posicionamento ativo no seu processo de cura envolvendo mudanças de atitudes, pensamentos e comportamentos. Nesse sentido, tais medicações podem ser analisadas aqui como formas importantes através das quais aspectos da doutrina espírita, como a necessidade da reforma íntima e do aperfeiçoamento moral, podiam ser repassados aos pacientes sem o dogmatismo de uma doutrinação religiosa stricto sensu, mas sim baseados numa lógica terapêutica.

As medicações prescritas no CAPC revelam-se ainda como uma forma de extensão do tratamento espiritual para o espaço doméstico, envolvendo a adoção de uma rotina de cuidados e formas de vinculação com o processo terapêutico espiritual para além da instituição. Assim, as gotinhas do floral 
e do SYG ou a ingestão da água fluidificada três vezes ao dia seriam formas estendidas do tratamento espiritual que demandam um compromisso com as orientaçôes do Centro, tais como manter os bons pensamentos, observar as emoçôes e ter fé no tratamento. Além disso, o uso desses medicamentos pode engendrar formas de agenciamento em torno da doença que envolve modos particulares de interação com essas substâncias para além da sua "prescrição medicamentosa", podendo levar a formas ritualizadas de uso, como fez uma senhora que disse ter inventado uma oração para rezar quando fosse tomar o SYG, embora essa recomendação não acompanhe a prescrição desse medicamento.

\section{CONSIDERAÇÕES FINAIS OU, O QUE PODE DIZER UMA IMAGEM DEPOIS DE MIL PALAVRAS?}

Em 2009, soube de uma denúncia feita contra o CAPC pela filha de um paciente que teria abandonado o tratamento alopático para tratarse apenas no Centro. Durante a pesquisa, jamais presenciei esse tipo de orientação sendo feita por qualquer voluntário da casa. Ao contrário, os pacientes ouviam repetidas vezes que eles deveriam manter o tratamento alopático simultaneamente ao tratamento espiritual. Após esse evento (que não resultou em sanção alguma contra o CAPC), grandes cartazes foram produzidos e espalhados pelo Centro e fôlderes foram entregues aos pacientes alertando sobre a necessidade de se manter o tratamento convencional (alopático). Se as mensagens orais não estavam surtindo efeito para alguns, talvez uma imagem servisse mais do que mil palavras para transmitir essa recomendação. A reprodução de uma caixa de medicamento genérico foi o meio escolhido para isso. Os dizeres do cartaz enfatizavam: "Entre o tratamento médico tradicional e o espiritual fique com os dois [...] o tratamento espiritual não substitui o tratamento médico tradicional". 
Cartaz alertando pacientes para a continuidade do tratamento alopático associado ao tratamento espiritual.

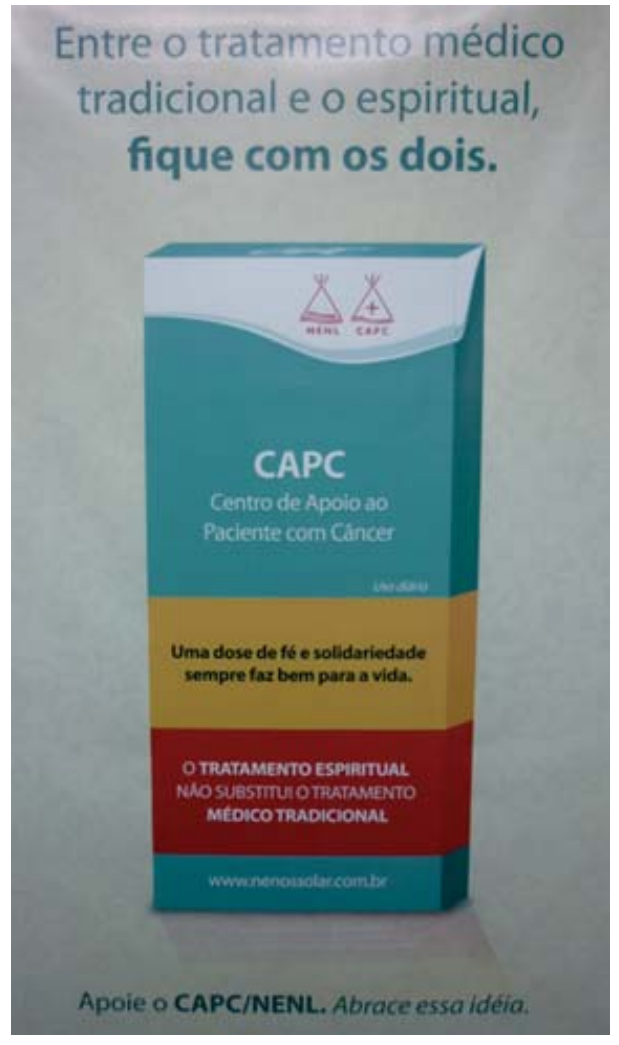

Fonte: Arquivo pessoal.

A partir do conceito de mimese, tal como explorado por Taussig (1993), analiso essa imagem como um lugar para produção de diferenças e semelhanças entre biomedicina e espiritismo no CAPC que reflete o processo histórico e inacabado da relação entre sistemas que se propõem distintos em seus métodos, mas que têm em comum o tratamento das aflições geradas pela doença.

Em Mimesis and Alterity, Taussig (1993) analisa como os índios Cuna absorveram o contato violento com o colonizador. $\mathrm{O}$ instrumento de resistência destas populaçôes foi recorrentemente "copiar" (mimetizar) o colonizador de uma forma que pudessem ter certo poder sobre ele. A forma geralmente escolhida eram os objetos de culto religioso, que ao serem "assemelhadas" aos colonizadores revelavam tanto o poder deles quanto um exercício de poder sobre eles. Assim, a mimese não seria mera imitação, mas 
uma forma de "recortar" e "modelar" o outro a fim de torná-lo semelhante, criando poder sobre ele no momento em que o captura, no momento em que ele é entendido, embora esse entendimento seja sempre um recorte, um momento na relação com esse outro através do qual os discursos sobre a diferença e as semelhanças são produzidos. A mimese, no entanto, registraria tanto a semelhança quanto a diferença de ser como e de ser outro, de modo que através dela não se procura continuar o mesmo (cópia literal), mas manter a semelhança através da diferença.

Embora sejam contextos etnográficos radicalmente distintos, o conceito de mimese pode ser acionado para analisar o lugar dos medicamentos nas práticas de cura do espiritismo, e especificamente nas do CAPC, pois ele aponta para as relações simbólicas e de poder envolvidas na produção de semelhanças e diferenças impetradas pela doutrina espírita com relação à biomedicina no Brasil. Quando inserem-se nas práticas terapêuticas espíritas, os medicamentos (homeopáticos, alopáticos e outros), como "coisas concretas" e símbolos da biomedicina, tanto afirmam quanto deslocam o poder da ciência médica ao propor uma relação entre elementos materiais e imateriais no processo de cura e adotar formas medicamentosas particulares, como a água fluidificada.

Nesse sentido, Giumbelli (2006) chama a atenção para as relações de introjeção, subversão e complementaridade que o espiritismo desenvolveu historicamente com a medicina oficial. Em sua análise, o autor destaca a mediunidade receitista e as cirurgias espirituais como duas práticas da terapêutica espírita nas quais podemos observar mimetizações que produzem simultaneamente a introjeção e a subversão de dinâmicas e lógicas da biomedicina. Por outro lado, o espiritismo buscou produzir certa complementaridade com a biomedicina ao tentar definir domínios específicos para sua atuação que envolve técnicas e concepções distintas para pensar a saúde e tratar as doenças. A análise de Giumbelli (1993) detém-se ao final do século XIX e à primeira metade do século XX quando o espiritismo ainda se firmava no campo religioso brasileiro. No entanto, essa mimese médica realizada pelos espíritas mantém-se atual e exige de seus praticantes e usuários um exercício sempre renovado de produção de significados envolvendo categorias, discursos, objetos, substâncias e valores retirados do domínio biomédico. 
Na relação histórica entre biomedicina e espiritismo, inegavelmente a primeira ocupou um lugar privilegiado a partir do qual estendeu sua teia discursiva e simbólica, da qual os medicamentos fazem parte. Assim, não é uma casualidade que o símbolo escolhido para "ilustrar" a importância do tratamento espiritual aliado ao alopático tenha sido uma caixa de medicamento. Essa imagem representa tanto um esforço de produzir semelhança quanto diferença com relação à biomedicina ao mostrar que o tratamento espiritual é diferente do biomédico, por isso não o substitui, mas é tão eficaz quanto ele, por isso também deve ser utilizado. Assim, se o paciente deseja ampliar suas chances de cura, ele ou ela deve ficar com os dois.

Desse modo, no CAPC, os medicamentos e sua imagem, assim como o jaleco, a roupa branca, o cheiro de iodo, os horários, o silêncio, a hierarquia das funçóes, os prontuários, o bisturi, os curativos, são momentos de recorte e modelagem desse outro (biomedicina), a fim de capturá-lo, criar poder sobre ele e usar esse poder da cópia para influenciar o que é copiado. Por outro lado, há uma série de práticas que são exclusivamente executadas pelos médicos e profissionais de saúde que ali trabalham e que atestam os lugares invioláveis desse outro que, ao marcar sua posição nesse espaço terapêutico empresta a ele sua legitimidade social e política.

Por fim, os medicamentos utilizados no CAPC podem ser pensados como formas de materializar a prática terapêutica espírita na qual geralmente é o invisível que age sobre o visível, a energia transforma a matéria e os espíritos operam os corpos dos vivos. Os remédios podem inverter essa relação sem alterar seus resultados, pois a separação entre material e imaterial no CAPC seria uma forma de convenção utilizada para resguardar o lugar particular e político de sistemas terapêuticos que se pretendem distintos, mas que de fato não impede aos diferentes atores que fazem parte desse cenário construir e desfazer conexões entre substâncias, fluídos, espíritos, pílulas, gestos, falas, imagens, médicos, preces e passes que compõem o cotidiano de suas práticas médico-espirituais. 


\section{REFERENNCIAS}

ALGRANTI, Miguel. Teorías etiológicas de la enfermedad y algunos principios terapéuticos en las prácticas de las Escuela Científico Basilio de Buenos Aires. Scripta Ethnologica, Vol. XXIX, p. 109-119, 2007.

AUBRÉE, Marion; LAPLANTINE, François. A mesa, o livro e os espiritos: gênese, evolução e atualidade do movimento social espírita entre França e Brasil. Maceió: EDUFAL, 2009.

BACH, Edward. Os remédios florais do Dr. Bach. São Paulo: Editora Pensamento, 2006.

CRUZ, Inácio M. N. Frade da. Doutor Fritz andou de disco voador: hibridizações e sincretismos na terapia espiritual de Chico Monteiro. 2007. Dissertação (Mestrado em Ciência da Religião). UFJF/PPGCR, Juiz de Fora, 2007.

GIUMBELLI, Emerson. O cuidado dos mortos: uma história da condenação e legitimação do Espiritismo. Rio de Janeiro: Ministério da Justiça, Arquivo Nacional, 1997.

. Espiritismo e medicina: introjeção, subversão, complementaridade. In: ISAIA, Artur César (Org.). Orixás e Espíritos: o debate interdisciplinar na pesquisa contemporânea. Uberlândia: EDUFU, 2006. p. 283-304.

GREENFIELD, Sidney. Cirurgias do Além: pesquisas antropológicas sobre curas espirituais. Petrópolis. RJ: Editora Vozes, 1999.

KARDEC, Allan. O Livro dos Médiuns. Araras: Instituto de Difusão Espírita, 1994.

KOSS-CHIOINO, Joan D. Spirit Healing, Mental Health, and Emotion Regulation. Zygon: Journal of Religion and Science, v. 40, n. 2, p. 409-421, 2005.

LEFÉVRE, Fernando. A função simbólica dos medicamentos. Revista de Saúde Pública, São Paulo, v. 17, p. 500-503, 1983. 
LUZ, Madel Therezinha. Natural, Racional, Social: razão médica e racionalidade científica moderna. Rio de Janeiro: Campus, 1988.

- A arte de curar versus a ciência das doenças: história social da homeopatia no Brasil. São Paulo: Dynamis, 1996.

MONTERO, Paula. Da doença à desordem: a magia na umbanda. Rio de Janeiro: Ediçōes Graal, 1985.

MOREIRA-ALMEIDA, Alexander; ALMEIDA, T. M.; GOLLNER, A. M. Cirurgia espiritual: uma investigação. Revista da Associação Médica Brasileira, v. 46, n. 3, p. 194-200, 2000.

RIVERA, Edil Torres. Espiritismo: The Flywheel of the Puerto Rican Spiritual Traditions. Revista Interamericana de Psicologia/Interamerican Journal of Psychology, v. 39, n. 2, p. 295-300, 2005.

ROCHA, Cristina. A globalização do espiritismo: fluxos do movimento religioso de João de Deus entre a Austrália e o Brasil. Revista de Antropologia, São Paulo: USP, v. 52, n. 2, p. 571-603, 2009.

SCHMIDT, Bettina E. Meeting the Spirits: Puerto Rican Espiritismo as Source for Identity, Healing and Creativity. Fieldwork in Religion, v. 3, n. 2, p. 178-194, 2009.

SOARES, Roger. As Associações Médico-Espíritas e a Difusão de seu Paradigma de Ciência e Espiritualidade. Debates do NER, Porto Alegre, ano 10, n. 15, p. 129-150, 2009.

TAUSSIG, M. Mimesis and Alterity: A Particular History of the Senses. New York: Routledge, 1993.

VAN DER GEEST, Sjaak; WHYTE, Susan Reynolds. O encanto dos medicamentos: metáforas e metonímias. Sociedade e Cultura, Goiânia, v. 14, n. 2, p. 457-472, 2011.

WARREN, Donald. A terapia espírita no Rio de Janeiro por volta de 1900. Religião e Sociedade, Rio de Janeiro: ISER/Ed. Campus, v. 11, n. 3, p. 56-83, 1984. 
A medicina espiritualizada: a homeopatia no Brasil do século XIX. Religião e Sociedade, Rio de Janeiro: ISER/Ed. Campus, v. 13, n. 1, p. 88-107, 1986.

WHO. World Health Organization. Traditional Medicine Strategy. 20022005. Geneva, 2002. 